\title{
Assessing the HIV rapid test in the fight against the HIVIAIDS epidemic in Trinidad
}

This article was published in the following Dove Press journal:

HIVIAIDS - Research and Palliative Care

6 August 2013

Number of times this article has been viewed

\section{Kameel Mungrue \\ Sayyad Sahadool \\ Reonda Evans \\ Shalini Boochay \\ Faith Ragoobar \\ Kiran Maharaj \\ Shade Green \\ Tamarah Pennerman \\ Oletlantse Tayopa}

Faculty of Medical Sciences,

Department of Paraclinical Sciences,

The University of the West Indies,

St Augustine, Trinidad and Tobago
Correspondence: Kameel Mungrue Faculty of Medical Sciences, Department of Paraclinical Sciences, The University of the West Indies, St Augustine,

Trinidad and Tobago

$\mathrm{Tel}+\mathrm{I} 8686452018$

Email kmungrue@fms.uwi.tt
Objective: To evaluate the Human immunodeficiency virus (HIV) rapid test as an effective tool in the response to the HIV/acquired immunodeficiency syndrome (AIDS) epidemic in Trinidad.

Design and methods: The study is comprised of a retrospective analysis of data collected from May 2008 to July 15, 2011 and a prospective arm of those tested during July 18, 2011 - August 30, 2011. During the prospective phase, blood samples were tested using rapid tests manufactured by Inverness Medical Innovation and Trinity Biotech followed by an enzyme-linked immunosorbent assay test, irrespective of the results of the rapid test. A structured questionnaire was administered to collect demographic data and risk behaviors. The study was conducted in one randomly selected primary health care facility of the eight that offered same-day HIV testing in Trinidad.

Results: A total of 297 persons participated in the prospective arm of the study and the rapid test was found to have a sensitivity of $100 \%$ and a specificity of $99.6 \%$. Females and those aged 20-29 years were most likely to participate. Over the study period, the number of persons who received rapid tests increased but the prevalence of positive HIV test results decreased from $4.4 \%$ in 2008 to $2.1 \%$ in 2011 . The main reasons for being tested were curiosity (38\%), results being obtainable the same day (27\%), and confidentiality (13\%). Approximately $50 \%$ of respondents reported more than one sex partner in the previous year while $14 \%$ used condoms regularly.

Conclusion: People need to know their own HIV status and that of their partners to make healthy decisions about sexual behavior. At the health facility studied, $2.6 \%$ of people who took the HIV rapid test were HIV positive.

Keywords: HIV testing tool, HIV status, rapid testing, voluntary testing and counseling (VCT)

\section{Introduction}

Human immunodeficiency virus (HIV) prevalence among adults in the Caribbean is estimated at $1.0 \%$ which is second to sub-Saharan Africa. ${ }^{1}$ The Joint United Nations Programme an HIV/AIDS (UNAIDS) estimated that at the end of 2009 in a population of 33 million, there were 240,000 people living with HIV in the Caribbean. ${ }^{2}$ At the end of 2009 in Trinidad and Tobago, the prevalence of HIV in adults aged 15-49 was $1.5 \%{ }^{3}$ This translates to approximately 19,500 people out of a population of 1.3 million who are HIV positive (HIV+), with more females than males in the two most vulnerable age groups: $15-19$ and $20-24 .{ }^{4}$ In response to the HIV/acquired immunodeficiency syndrome (AIDS) epidemic, the government of the Republic of Trinidad and Tobago, through the National AIDS Coordinating Committee (NACC), has implemented a National Strategic Plan (NSP). This plan focuses on five areas: 
(1) prevention, (2) program management and coordination, (3) advocacy and human rights, (4) treatment and support for people living with HIV/AIDS, and (5) surveillance and research. $^{5}$

In the execution of the NSP, the NACC has implemented two programs: (1) the "What's Your Position" (WYP) campaign, and (2) voluntary counseling and testing (VCT) through the same-visit HIV testing program (SVHTP). The WYP campaign focuses on sensitizing and educating the population about the HIV/AIDS epidemic using mass media. The population is encouraged through these messages to make informed choices. The recommendations include: (1) abstinence, (2) being faithful, (3) consistent and correct condom use, and (4) getting tested. Recommendations $1-3$ were evaluated by Jurawan et al and proved to be effective. $^{6}$

The SVHTP has not been similarly evaluated. In May 2008, rapid testing for HIV in Trinidad and Tobago became a structured public health intervention. The SVHTP utilizes the Determine $^{\mathrm{TM}}$ Rapid Test (DRT) (Alere, Waltham, MA) and the Uni-Gold Recombigen ${ }^{\mathrm{TM}}$ (Trinity Biotech, Bray, Ireland) HIV test (URH). The DRT has been approved for use by UNAIDS and the URH has been granted US Food and Drug Administration (FDA) approval. In the event of a discordant result a third test is employed, using the FDA approved HIV Stat-Pak ${ }^{\circledR}$ manufactured by Chembio Diagnostic Systems (Medford, NY). Both kits have had their quality assured by Von Knorring et al who found the sensitivity and specificity of the DRT to be $98.95 \%$ and $99.83 \%$, respectively. The URH had a sensitivity of $99.30 \%$ and a specificity of $99.96 \%{ }^{7}$ The DRT is an HIV-1/2 Ag/Ab Combo rapid testing kit. This kit can simultaneously detect the HIV p24 antigen as well as antibodies to HIV-1 and HIV-2 in serum, plasma, and whole blood. It is a simple two-step rapid test that requires no refrigeration, no power, no water, minimal training, and a finger stick for blood sample collection. The process takes 20 minutes to produce a result. ${ }^{8}$ The URH test, developed by Trinity Biotech, detects antibodies to HIV-1 in serum, plasma, and whole blood. ${ }^{9}$ Testing is voluntary, confidential, and free, and is performed at eight designated primary health care facilities only, out of approximately 100 such facilities throughout the island. Confirmatory tests are only performed for positive tests.

In some clinical trials conducted using DRT in Europe, Asia, Africa, and Latin America the sensitivity was 100\% while the antibody line had a specificity of $99.21 \%$ and the antigen line had a specificity of $99.61 \% .{ }^{10}$ On the other hand, Gray et al reported that the HIV rapid test may have a low specificity $\left(90.4 \%\right.$ ), yielding up to $43.7 \%$ false positives. ${ }^{11}$
False positives cause clients unnecessary anxiety and psychological trauma. Bassett and colleagues studied patients who tested HIV negative by rapid testing and showed that of 705 clients who tested negative by rapid testing, 11 (1.6\%) were HIV-infected on confirmatory testing. ${ }^{12}$ Similarly, a false negative result delays treatment with antiretroviral medication, thereby risking progression to AIDS as well as promoting transmission of HIV. In cases where the client is pregnant, a false negative result may lead to mother-to-child transmission.

The aim of this study was to evaluate the SVHTP which uses rapid testing as an effective strategy in response to the HIV/AIDS epidemic in Trinidad. The study also identified segments of the population that utilized the rapid testing and their reasons for accessing this service.

\section{Methods}

Data were collected at the Queen's Park Counselling Centre and Clinic (QPCCC) and the population for the study was all persons seeking HIV testing from 2008 at the facility. The center was chosen using a simple random sampling technique from the eight primary health care facilities that offer same day HIV rapid testing.

There were two arms of the study: (1) a retrospective arm which used data collected between May 2008 and April 2011, and (2) a prospective arm in which data was collected from May 2011. In the retrospective arm of the study, testing records of previous clients attending the QPCCC were systematically reviewed. Data on age, gender, the number of rapid tests performed, and the result were collected.

In the prospective arm of the study, a structured pretested interview questionnaire was administered after verbal consent at step 4 in the testing algorithm (Figure 1). The questionnaire focused on the following themes: (1) characteristics of the clients who chose to have rapid testing, (2) their reasons for accessing the service, and (3) their sexual practices and habits.

In the current program, only participants who tested positive by rapid testing had a confirmatory test. Participants testing negative were discharged from the clinic without any subsequent follow-up. However, in the prospective arm of the study, all participants who had the rapid test performed also had an enzyme-linked immunosorbent assay (ELISA) test performed at the same time, irrespective of the rapid test result.

All data were stored on a password protected file and analyzed using SPSS version 17 (IBM Corp, Armonk, NY). We reported proportions and used a two-tailed $t$-test, and the chi-squared test, to establish significance, set at $P \leq 0.05$. 


\section{Step 1}

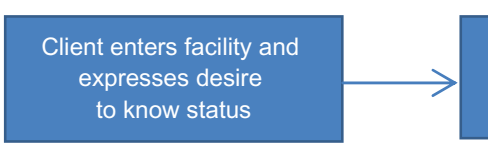

Step 2

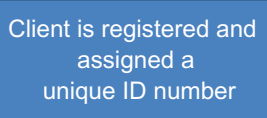

Client is registered and

assigned a

unique ID number

Step 3

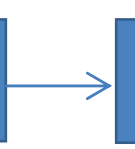

Client sent to phlebotomist

and $5 \mathrm{ml}$ venous

blood taken

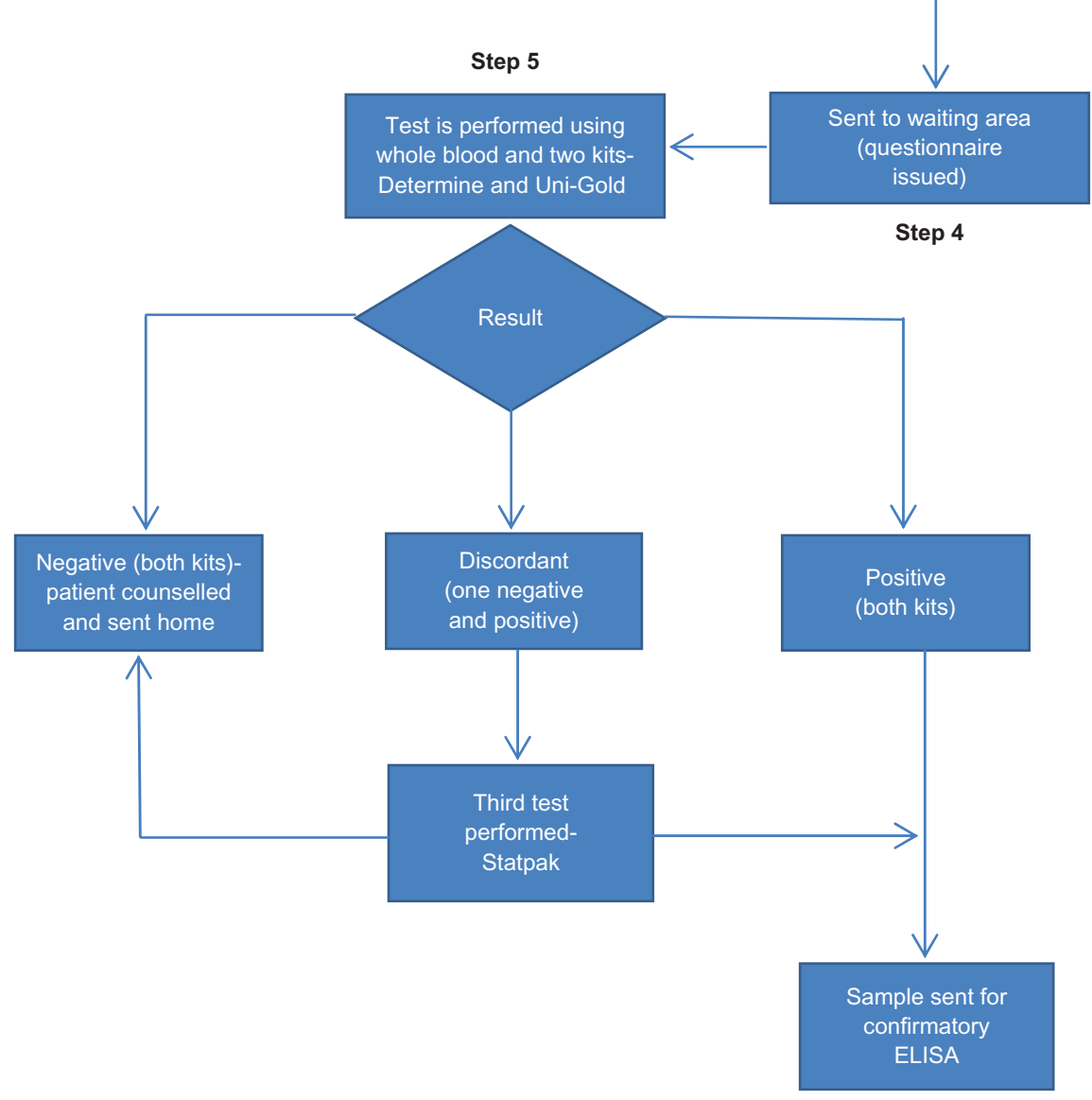

Figure I HIV rapid testing algorithm.

The protocol for the study was approved by the Ethics Committee of the University of the West Indies.

\section{Results}

The total number of rapid tests performed during the study increased three-fold from 1652 in 2008, when the program started, to 5253 in 2010 (Table 1). The prevalence of HIV testing among persons $\geq 18$ years who actually received an HIV rapid test for the two calendar years of complete data (ie, 2009 and 2010) was 43.7 per 10,000 population in 2009 and 54.6 per 10,000 in 2010. Compared with the number of reported cases, rapid testing was detecting an average of $2.6 \%$ of all cases reported (Table 2 ). In point of fact, as more tests were performed, there was no significant change in the total number of cases reported. For every time period, more women than men were responding to SVHTP

Table I The number of positive HIV rapid test by gender, calendar year, and prevalence per 10,000 population

\begin{tabular}{|c|c|c|c|c|c|c|c|}
\hline \multirow[t]{2}{*}{ Year } & \multicolumn{2}{|c|}{$\begin{array}{l}\text { Actual number of HIV rapid } \\
\text { tests performed by gender }\end{array}$} & \multicolumn{3}{|c|}{$\begin{array}{l}\text { No of positive HIV rapid tests } \\
\text { by gender and proportion (\%) }\end{array}$} & \multirow[t]{2}{*}{$\begin{array}{l}\text { Total no of rapid } \\
\text { tests performed }\end{array}$} & \multirow{2}{*}{$\begin{array}{l}\text { Testing prevalence } \\
\text { rate (per } 10,000 \\
\text { population) }\end{array}$} \\
\hline & Male & Female & Male & Female & Total cases & & \\
\hline May-Dec 2008 & 766 & 886 & $34(4.4)$ & $39(4.4)$ & 73 & 1652 & 17.2 \\
\hline Jan-Dec 2009 & 1935 & 2267 & 75 (3.9) & $54(2.4)$ & 129 & 4202 & 43.7 \\
\hline Jan-Dec 2010 & 2284 & 2969 & $60(2.6)$ & $75(2.5)$ & 135 & 5253 & 54.6 \\
\hline Jan-July 201I & 1573 & 1900 & $44(2.8)$ & $30(1.6)$ & 74 & 3473 & 36.1 \\
\hline
\end{tabular}


Table 2 Proportion of HIV detected by rapid testing by gender and year

\begin{tabular}{lllll}
\hline Gender & \multicolumn{4}{l}{ Proportion (\%) } \\
\cline { 2 - 5 } & $\mathbf{2 0 0 8}$ & $\mathbf{2 0 0 9}$ & $\mathbf{2 0 1 0}$ & $\mathbf{2 0 1 1}$ \\
\hline Male & 2.1 & 1.8 & 1.1 & 1.3 \\
Female & 2.4 & 1.3 & 1.4 & 0.9 \\
\hline
\end{tabular}

by seeking rapid testing. However, while more women were seeking testing, more men were being tested positive.

During the prospective arm of the study 297 participants were initially enrolled. Each participant had a rapid test and an ELISA test performed. However only 247 (83.2\%) consented to participate in the interview-administered questionnaire. The rapid test was positive in 45 (11.4\%) participants but confirmed by ELISA in only 44: hence, there was only one false positive test (Table 3). No client had a false negative rapid test. Thus, the sensitivity and the specificity was $100 \%$ and $99.6 \%$, respectively (Table 3 ).

Further analysis of data collected from the prospective arm of the study showed that the majority of the people accessing rapid testing were in the age group 20-24 years (Table 4). This group (20-24 years) as well as the $\geq 51$ age group accounted for the highest seropositive rates, $18.2 \%$ each, both by rapid test and ELISA.

Of the 247 participants who consented to the interview-administered questionnaire, people of African ethnicity constituted the majority $(60.7 \%)$ of respondents. Recreational drug use was reported by $16.6 \%$ of respondents, of which $10.5 \%$ were regular users. Overall, approximately $50 \%$ of respondents reported having more than one sexual partner in the previous year. Similarly, just over half of the respondents reported tobacco use (both past and current) and 216 (87.5\%) reported alcohol consumption. A total of $75.3 \%$ reported using condoms, however, only $14.2 \%$ reported using condoms "always". When asked as to how they became aware of rapid testing, more respondents reported from a friend $(127,51.4 \%)$ than from the media $(72,29.1 \%)$, while health care providers $(12,4.8 \%)$ were the least common source of information about rapid testing.

Table 3 Results of rapid tests and confirmatory tests performed prospectively

\begin{tabular}{llll}
\hline Result of rapid test & \multicolumn{2}{l}{ ELISA test result } & Total \\
\cline { 2 - 3 } & Negative & Positive & \\
\hline Negative & 252 & 0 & 252 \\
Positive & $\mathrm{I}$ & 44 & 45 \\
Total & 253 & 44 & 297 \\
\hline
\end{tabular}

While there was a plethora of reasons given by participants for seeking a rapid test, the main reasons reported were curiosity $(38.1 \%)$, convenience $(27.1 \%$; ie, results can be obtained on the same day), knowledge of their status (20\%), and confidentiality (12.6\%). Reasons such as a puncture wound or verification of HIV negative status for employment accounted for $<2 \%$ of participants (Table 5 ). The majority of participants $(69.6 \%)$ reported having a previous test. The two most common reasons reported by participants for being previously tested were (1) to know their status (23.5\%), and (2) curious to find out their status $(10.15 \%)$.

\section{Discussion}

An important finding of this study is the progressive increase in the number of persons utilizing rapid testing (ie, from 1625 in 2008 to 5253 in 2011) since the commissioning of SVHTP as a public health strategy in 2008 in Trinidad. However, this only contributed $2.6 \%$ of the annual reported cases of new infections. Nevertheless, the prevalence of HIV testing by SVHTP is acceptable, compared ideally to 30-40 per 10,000 population in high prevalence settings. Various factors have been identified for the low uptake of VCT: (1) socio-economic factors such as age, ${ }^{13-17}$ marital status, ${ }^{16}$ educational level, ${ }^{14,18,19}$ occupation, ${ }^{15}$ household wealth, ${ }^{18}$ and area of residence; ${ }^{16}$ (2) social factors such as fear of unsolicited disclosure, fear of stigma, fear of discrimination, ${ }^{14,15,17,20-22}$ and client-counselor dynamics, including lack of confidentiality; ${ }^{19,23,24}$ (3) proximity and access to VCT site; ; $^{1423,25-27}$ (4) HIV knowledge, including prior knowledge of VCT sites and HIV risk perception, and HIV risk behavior; ${ }^{15,16,18,19,28,29}$ and (5) health status. ${ }^{13,15,16}$ Although the focus of this study was not to identify barriers to VCT all these factors may have contributed to the low utilization of VCT in our setting. Yet the seropositivity rate was higher than the 1/1000 threshold deemed to be cost effective for routine testing. ${ }^{30}$

Table 4 Relationship between age and seropositivity

\begin{tabular}{lll}
\hline Age (years) & $\begin{array}{l}\text { Frequency } \\
\mathbf{n}(\%)\end{array}$ & $\begin{array}{l}\text { Rapid test and ELISA (+) } \\
\mathbf{n}(\%)\end{array}$ \\
\hline $14-19$ & $4 \mathrm{I}(13.8)$ & $2(4.5)$ \\
$20-24$ & $75(25.3)$ & $8(18.2)$ \\
$25-29$ & $50(16.8)$ & $6(13.6)$ \\
$30-34$ & $34(11.4)$ & $4(9.1)$ \\
$35-39$ & $25(8.4)$ & $5(11.4)$ \\
$40-44$ & $22(7.4)$ & $5(11.4)$ \\
$45-50$ & $22(7.4)$ & $5(11.4)$ \\
$\geq 51$ & $21(7.1)$ & $8(18.2)$ \\
Undisclosed & $7(2.4)$ & $1(2.3)$ \\
\hline
\end{tabular}


Table 5 Various reasons for taking the test

\begin{tabular}{ll}
\hline Reason for taking the test & Proportion (\%) \\
\hline Curiosity & 38.1 \\
Convenience & 27.1 \\
Knowledge of their status & 20 \\
Confidentiality & 12.6 \\
Other reasons & $<2$ \\
\hline
\end{tabular}

The implications of this finding are critical for the future control of the HIV/AIDS epidemic in Trinidad and, by extension the developing world, as HIV testing is the "critical gateway" to treatment. ${ }^{31}$ Over the last decade, dramatic increases in funding for HIV/AIDS and substantial reductions in the price of antiretroviral therapy (ART) have promised to transform the life expectancy of HIV+ individuals in the developing world, particularly as early diagnosis and timely treatment with ART can increase life expectancy. In the Caribbean, this promise has yet to be realized, while in other parts of the world, during the period 1996-2008, life expectancy in people treated for HIV infection increased by over 15 years. ${ }^{32}$ An additional benefit of increased HIV/AIDS funding and lower costs for ART has been a reduction in mortality rates. Harrison et al reported a reduction in mortality rates with $\mathrm{HIV}+$ persons on $\mathrm{ART},{ }^{33}$ while Kitahata et al reported a $69 \%$ increase in risk of death for deferred vs early therapy in patients with a CD4+ count of 351-500 cells $/ \mathrm{mm}^{3}$, and a $94 \%$ increase in risk of death for deferred vs early therapy in patients with a CD4+ count $>500$ cells $/ \mathrm{mm}^{3} .^{34}$ Apart from individual benefits, an important public health benefit has been the reduction in transmission. Cohen and colleagues have demonstrated that ART was as effective as condoms in preventing the transmission of HIV. ${ }^{35}$ This is in addition to evidence provided by Mark et al, who showed that among $25 \%$ who were unaware of their HIV positive status $54 \%$ were contributing to new infections. ${ }^{36}$

The main institutional response to low HIV testing has been to focus on the expansion of clinic-based testing using two approaches: (1) increase the number of sites - fixed and mobile - in which people are offered VCT services, and (2) to substitute what is alternately referred to as provider-initiated, routine, or opt-out testing for more traditional VCT approaches. ${ }^{37,38} \mathrm{~A}$ third approach suggests that the most effective solution to low testing prevalence is to substitute home-based for clinic-based tests. Thus far, supporters of this shift have justified their claims in two ways. First, preference for home-based testing compared to facility-based alternatives, as demonstrated in studies done in Africa - although in the context of smaller research studies - and second, wherever home-based VCT has been tried it has generated a massive increase in proportions tested in comparison to more traditional clinic-based VCT. ${ }^{39-41}$ Our findings provide preliminary evidence that the current SVHTP program may not be achieving its intended results, suggesting further monitoring and evaluation.

Another important finding of the study was the difference in HIV testing rates between men and women. Since the introduction of rapid testing in 2008, the HIV testing rate amongst the women has been on a steady decline as compared to the males. According to a survey done in Tobago by the Family Planning Association along with other bodies, girls aged 15-19 were six times as likely to be HIV+ as compared to boys the same age. ${ }^{42}$ Studies show that women who are more educated are more likely to know how to prevent HIV infection, to delay sexual activity, and to take measures to protect themselves from infection. ${ }^{43}$ This can directly lead to a decrease in HIV testing rates in women. The assumption could be made that the use of mass media has an effect only in the female population, but this can only be confirmed with further studies.

In our study, the highest seropositivity was seen in the age group 20-24 years. This group has demonstrated a high percentage of risk taking behavior with the most alcohol consumption, recreational drug consumption, and inconsistent condom use. However, the survey done in Tobago indicated the highest rates for these risk factors, was in the 15-19 age group. The biggest contributing factor to this discrepancy was the operating hours of the clinic. The clinic runs from $8: 00 \mathrm{am}-4: 00 \mathrm{pm}$, however, testing is only available until lunch time because the testers are needed in other facilities. This time correlates with school hours, especially for those who belong to the 15-19 age group (high school). Thus, these individuals would not be able to access the clinic and they would not be accurately represented in the data.

The data also showed that awareness of the program was predominantly from friends. In other words, the media and health care providers were not significant facilitators of the program. Therefore, in order to utilize this finding, we suggest the use of social networking (eg, Facebook and Twitter) as well as making existing facilities more user friendly towards adolescents and young adults. The latter can be achieved by improving efficiency through the provision of better resources such as laboratory facilities and staff (clients often complain of long waiting times before being tested, and for receiving results of confirmatory tests).

Since 2002, the government of Trinidad has made free HIV/ AIDS treatment accessible to all citizens. An HIV+ rapid test 
is followed by an ELISA confirmation test. While awaiting confirmatory results, the client is referred to a special center where both a CD4 count and viral load tests are performed. On confirmation of an HIV+ result, the client's CD4 to viral load ratio determines when treatment with antiretrovirals will begin. A client with a high CD4 to viral load ratio will not begin immediate treatment; instead, they are monitored until their CD4 to viral load ratio decreases to a threshold value. Clients with a low CD4 to viral load ratio begin treatment immediately. According to the World Health Organization, ART should be initiated at a CD4 threshold of 350 cells $/ \mathrm{mm}^{3}$ for all HIV+ people. ${ }^{44}$ The CD4 to viral load ratio of all clients who are administered antiretrovirals is periodically monitored to determine the effectiveness of the treatment and to track the progression of the disease. Thus, the rapid test acts as an important conduit to monitoring and treatment. On the other hand, SVHTP was not linked with other reproductive health services, particularly family planning services and drug rehabilitation services - an important gap between rapid testing and other critical services that may have an impact on new infections.

Rapid testing has also impacted on the training of HIV care providers. An HIV/AIDS health care provider must attain a certificate in the field of counseling, and must also be approved as a certified tester by the Ministry of Health. To achieve certification, the individual must undergo training and be certified by the Caribbean Epidemiology Centre or the Centre for Disease Control for HIV rapid testing and its methodologies, or be a medical laboratory technician who is qualified to perform rapid, automated, and manual ELISA tests.

The study also identified patterns of condom use: $24.7 \%$ of respondents reported never using a condom, and $61.1 \%$ only sometimes. Unprotected anal sex is the sexual behavior with highest risk for HIV transmission. Nondisclosure of HIV infection as well as inconsistent and incorrect condom use has a synergistic effect in promoting HIV infection. Therefore, interventions delivered in these settings can facilitate modification of risky sexual behaviors.

This finding continues to highlight an area often overlooked in HIV prevention: specifically, the conceptualization of how people constitute and understand the notion of risk and safety. This is a necessary step before appropriate counseling is administered. This is against a background of other risk taking behaviors such as multiple partners (50.6\%), smoking tobacco $(53.8 \%)$, use of recreational drugs $(16.6 \%)$, and alcohol consumption (87.5\%) all identified in this study. Heavy alcohol use can lead to HIV transmission by affecting judgment and reducing inhibitions, thereby diminishing perceived risk or excusing behaviors otherwise considered socially unacceptable. ${ }^{45}$

The findings in this study are subject to several limitations. A major limitation is that only one of the eight centers was studied, mainly because of the quality of data available. In addition, in order to satisfy ethical approval by various consenting bodies requesting strict confidentiality, the data was not allowed to be linked so that characteristics such as drug use, smoking, and alcohol consumption could not be linked to the likelihood of being HIV infected, nor allow the further analysis of calculating odds ratios. Venue-based, time-location sampling methods were used which is likely to lead to two errors: selection bias and generalizability, as estimates are generated for hard-toreach populations where sampling frames of the individual members of those populations do not exist or are difficult to construct. Because an interviewer administered the questionnaire, certain behaviors might have been underreported or over-reported. For example, participants might have underreported socially undesirable behaviors (eg, drug use) or might have over-reported socially desirable behaviors (eg, using condoms or being tested recently). In addition, all clients who tested negative were discharged and lost to follow up.

\section{Conclusion}

Multiple indicators are relevant to HIV risk and prevention. Therefore, people need to know their own HIV status and that of their partners to make healthy decisions about sexual behavior. VCT is an essential service for both prevention and treatment. We provide evidence that the current SVHTP contributed to only $2.6 \%$ of the reported cases of HIV+ annually and that the prevalence of HIV testing was low.

\section{Disclosure}

The authors report no conflicts of interest in this work.

\section{References}

1. UNAIDS, Caribbean [website on the Internet]. Geneva: UNAIDS; 2010. Available from: http://www.unaids.org/en/regionscountries/regions/ caribbean/. Accessed March 9, 2011.

2. UNAIDS. Global Report Fact Sheet Caribbean. Geneva: UNAIDS; 2010. Available from: http://www.unaids.org/documents/20101123_ FS_carib_em_en.pdf. Accessed March 9, 2011.

3. UNAIDS, Trinidad and Tobago [website on the Internet]. Geneva: UNAIDS; 2010. Available from: http://www.unaids.org/en/ regionscountries/countries/trinidadandtobago/. Accessed March 9, 2011.

4. UNAIDS. Trinidad and Tobago. Geneva: UNAIDS; 2004. Available from: http://data.unaids.org/Publications/Fact-Sheets01/trinidadtobago_en.pdf. Accessed March 11, 2011. 
5. United Nations Development. Development of the National Strategic Plan on HIV/AIDS 2010-2015 for the Republic of Trinidad and Tobago. Port of Spain: United Nations Development Programme; 2011. Available from: http://www.undp.org.tt/procurement/TOR-National\%20Strategic\%20Plan.pdf. Accessed January 27, 2011.

6. Jurawan K, Dindial D, Hosein S, King D, Sahadeo A, Mungrue K. An evaluation of intervention strategies for HIV/AIDS in Trinidad and Tobago (2000-2007). Int J Adolesc Med Health. 2009;21(4):581-589.

7. Von Knorring, Gafos M, Ramokonupi M, Jentsch U; MDP Team. Quality control and performance of HIV rapid tests in a microbicide clinical trial in rural KwaZulu-Natal. PLoS One. 2012;7(1): e30728.

8. Inverness Medical Innovation Inc. Features and Benefits [webpage on the Internet]. Waltham: Inverness Medical Innovation Inc; 2011 Available from: http://www.determinetest.com/hiv1\%E2\%81\%842_ combo/features_benefits.aspx. Accessed January 27, 2011.

9. Trinity Biotech PLC. Uni-Gold ${ }^{T M}$ Recombigen ${ }^{\circledR} H I V$. Bray: Trinity Biotech PLC; 2008. Available from: http://www.unigoldhiv.com/ package_insert.pdf. Accessed July 10, 2011

10. Inverness Medical Innovation Inc. Determine Performance Data [webpage on the Internet]. Waltham: Inverness Medical Innovation Inc; 2011. Available from: http://www.determinetest.com/hiv1\%E2\%81\%842_ combo/performance_data.aspx. Accessed March 9, 2011.

11. Gray RH, Makumbi F, Serwadda D, et al. Limitations of rapid HIV-1 tests during screening for trials in Uganda: diagnostic test accuracy study. BMJ. 2007;335(7612):188.

12. Bassett IV, Chetty S, Giddy J, et al. False Negative Rapid HIV Tests in an Outpatient Department in Durban, South Africa [poster 98]. Proceedings of the 15th Conference on Retroviruses and Opportunistic Infections; February 3-6, 2008; Boston, MA.

13. Shisana O, Rehle T, Simbayi LC, et al, editors. South African National HIV Prevalence, Incidence, Behaviour, and Communication Survey, 2008. Cape Town: HSRC Press; 2005.

14. Hutchinson PL, Mahlalela X. Utilization of voluntary counselling and testing services in the Eastern Cape, South Africa. AIDS Care. 2006;18(5):446-455.

15. Ma W, Detels R, Feng Y, et al. Acceptance of and barriers to voluntary HIV counselling and testing among adults in Guizhou province, China. AIDS. 2007;21 Suppl 8:S129-S135.

16. Wringe A, Isingo R, Urassa M, et al. Uptake of HIV voluntary counselling and testing services in rural Tanzania: implications for effective HIV prevention and equitable access to treatment. Trop Med Int Health. 2008;13(3):319-327.

17. Bwambale FM, Ssali SN, Byaruhanga S, Kalyango JN, Karamagi CA. Voluntary HIV counselling and testing among men in rural western Uganda: implications for HIV prevention. BMC Public Health. 2008;30(8):263.

18. Kalichman SC, Simbayi LC. HIV testing attitudes, AIDS stigma, and voluntary HIV counselling and testing in a black township in Cape Town, South Africa. Sex Transm Infect. 2003;79(6): 442-447.

19. Gage AJ, Ali D. Factors associated with self-reported HIV testing among men in Uganda. AIDS Care. 2005;17(2):153-165.

20. Haile BJ, Chamber JW, Garrison JL. Correlates of HIV knowledge and testing: Results of a 2003 South African HIV Survey. J Black Stud. 2007;38(2):194-208.

21. Morin SF, Khumalo-Sakutukwa G, Charlebois ED, et al. Removing barriers to knowing HIV status: same-day mobile HIV testing in Zimbabwe. J Acquir Immune Defic Syndr. 2006;41(2): 218-224.

22. Obermeyer CM, Osborn M. The utilization of Testing and Counseling for HIV: A review of the social and behavioural evidence. Am J Pub Health. 2007;97(10):1762-1774.

23. Radebe MA. Perceptions of employees about Voluntary Counselling and Testing (VCT) at a motor manufacturing industry [MA thesis]. University of Pretoria: Pretoria, Department of Social Work and Criminology; 2006.
24. Varga C, Brookes H. Factors influencing teen mothers' enrollment and participation in prevention of mother-to-child HIV transmission services in Limpopo Province, South Africa. Qual Health Res. 2008;18(6): 786-802.

25. Birdsall K, Hajiyiannis H, Nkosi Z, Parker W. Voluntary Counselling and Testing (VCT) in South Africa: Analysis of calls to the national AIDS helpline. Johannesburg: Centre for Aids Development, Research and Evaluation (CADRE); 2004.

26. Pronyk PM, Kim JC, Makhubele MB, Hargreaves JR, Mohlala R, Hausler HP. Introduction of voluntary counselling and rapid testing for HIV in rural South Africa: from theory to practice. AIDS Care. 2002;14(6):859-865.

27. Pronyk PM, Kim JC, Makhubele MB, Hargreaves JR, Mohlala R, Hausler HP. Introduction of voluntary counselling and rapid testing for HIV in rural South Africa: from theory to practice. AIDS Care. 2002;14(6):859-865.

28. Boulle A, Hilderbrand K, Menten J, et al. Exploring HIV risk perception and behaviour in the context of antiretroviral treatment: results from a township household survey. AIDS Care. 2008;20(7): 771-781.

29. Mutevedzi T, Routh J, Khumalo-Sakutukwa G, Fritz K, Morin S. Removing barriers to knowing HIV status: A comparison of testers and non-testers in Sub-Saharan Africa 2002. Proceedings of the 14th International AIDS Conference; July 7-12, 2002; Barcelona, Spain.

30. Thornton AC, Delpech V, Kall MM, Nardone A. HIV testing in community settings in resource-rich countries: a systematic review of the evidence. HIV Med. 2012;13(7):416-426.

31. Rennie S, Behets F. Desperately seeking targets: the ethics of routine HIV testing in low-income countries. Bull World Health Organ. 2006; 84(1):52-57.

32. May M, Gompels M, Deplesh V, et al. Impact of late diagnosis and treatment on life expectancy in people with HIV-1: UK Collaborative HIV Cohort (UK CHIC) Study. BMJ. 2011;343:d6016.

33. Harrison KM, Song R, Zhong X. Life expectancy after HIV diagnosis based on national HIV surveillance data from 25 states, United States. JAIDS. 2010;53(1):124-130.

34. Kitahata MM, Gange SJ, Abraham AG, et al. Effect of early versus deferred antiretroviral therapy for HIV on survival. $N$ Engl $J$ Med. 2009;360(18): 1815-1826.

35. Cohen MS, Chen YQ, McCauley M, et al. Prevention of HIV-1 infection with early antiretroviral therapy. $N$ Engl J Med. 2011;365(6): 493-505.

36. Mark G, Crepaz N, Janssen RS. Estimating sexual transmission of HIV from persons aware and unaware that they are infected with the virus in the USA. AIDS. 2006;20(10):1447-1450.

37. Marum E, Taegtmeyer M, Chebet K. Scale-up of voluntary HIV counseling and testing in Kenya. JAMA. 2006;296(7):859-862.

38. Beckwith CG, Flanigan TP, del Rio C, et al. It is time to implement routine, not risk-based, HIV testing. Clin Infect Dis. 2005;40(7): $1037-1040$.

39. Koo DJ, Begier EM, Henn MH, Sepkowitz KA, Kellerman SE. HIV counseling and testing: less targeting, more testing. Am J Public Health. 2006;96(6):962-964.

40. Weiser SD, Heisler M, Leiter K, et al. Routine HIV testing in Botswana: a population-based study on attitudes, practices, and human rights concerns. PLoS Med. 2006;3(7):e261.

41. Greenwald JL, Burstein GR, Pincus J, Branson B. A rapid review of rapid HIV antibody tests. Curr Infect Dis Rep. 2006;8(2):125-131.

42. Early Sexual Activity Raises HIV Risk for Trinidad and Tobago Girls [webpage on the Internet]. Washington: Population Reference Bureau; 2000. Available from: http://www.prb.org/Articles/2000/EarlySexualActivityRaisesHIVRiskforTrinidadandTobagoGirls.aspx. Accessed March 25, 2012.

43. Women and HIV/AIDS Confronting the Crisis- Education [webpage on the Internet]. New York: UNFPA; 2004. Available from: http:// www.unfpa.org/hiv/women/report/chapter5.html. Accessed March 25, 2012. 
44. New HIV recommendations to improve health, reduce infections and save lives. Geneva: WHO; 2009. Available from: http://www.who.int/ mediacentre/news/releases/2009/world_aids_20091130/en/index.html. Accessed March 20, 2012.
45. Alcohol and AIDS: A guide to research issues and opportunities [webpage on the Internet]. NIAAA; 2002. Available from: http://pubs. niaaa.nih.gov/publications/aa57.htm. Accessed March 25, 2012.

\section{Publish your work in this journal}

HIV/AIDS - Research and Palliative Care is an international, peerreviewed open-access journal focusing on advances in research in HIV, its clinical progression and management options including antiviral treatment, palliative care and public healthcare policies to control viral spread. The journal welcomes original research, basic science, clinical \& epidemiological studies, reviews \& evaluations, expert opinion \& commentary, case reports \& extended reports. The manuscript management system is completely online and includes a very quick and fair peer-review system. Visit http://www.dovepress.com/ testimonials.php to read real quotes from published authors.

Submit your manuscript here: http://www.dovepress.com/hivaids---research-and-palliative-care-journal 